Rathinam George Sahaya Nixon

Rengarajan Sathish

Bhulok Sundar Mohanty

https://doi.org/10.21278/TOF.42405

ISSN 1333-1124

eISSN 1849-1391

\title{
CHARACTERIZATION OF A FRICTION SURFACED STAINLESS STEEL COATING ON MEDIUM CARBON STEEL
}

\begin{abstract}
Summary
In this study, a novel attempt was made to prevent corrosion on an EN8 medium carbon steel substrate by coating it with AISI 316 stainless steel using the friction surfacing method. The ram tensile test was conducted on the sample and maximum bond strength of $504 \mathrm{MPa}$, with a minimum coating thickness of $3.06 \mathrm{~mm}$, was obtained. Three peak values of 42.19, 43.12 and 49.07 were obtained by the X-ray diffraction technique. A salt spray test was conducted on the samples. Two different dark yellow and dark brown rusts were observed on the substrate after 50 and 250 hours of treatment respectively. It has been found that the stability of the coating in a corrosive environment is demonstrated by its capacity to resist corrosion during the period of immersion in the electrolyte at $70^{\circ}$, indicating a capacitive behaviour. However, the phase angle of exposure to electrolyte for the AISI316-EN8 system became more resistive $\left(65^{\circ}\right)$ than for EN8 (45). The coating thickness has been greatly influenced by process parameters such as traverse speed, axial load and rotational speed. Coating combinations of such materials improve the service life in marine and automobile applications.
\end{abstract}

Key words: $\quad$ mechtrode, substrate, bond strength, coating, friction surfacing.

\section{Introduction}

Deterioration of the base metal caused by corrosion and wear in the marine environment leads to a heavy loss of the base metal. To avoid this, coatings are deposited by different coating process such as chemical (sacrificial coating, galvanizing, electrolyte coating) and mechanical coating process. Mechanical metal coating such as hard facing and thermal spraying processes are fusion-based processes which affects the metal by dilution, porosity, undesirable phase changes and low metallurgical bonding [1,2]. Friction surfacing is defined as a solid state deposition process which provides zero dilution on the metallic coating [3]. In this process, a rotating consumable rod with specified diameter is used as a mechtrode and pressed under an axial load on the work piece material called substrate. Heat dissipation is caused by friction so that rigorous visco plastic deformations occur at the intimate contact between the mechtrode and the substrate [4].Traversing motion is fed to the substrate continuously, the rubbing action occurs, a dynamic recrystallization zone is introduced, and a fine grained structure and good metallurgical bonding are obtained due to inter-diffusion [5]. Process parameters, such as axial force, traverse speed, and rotational speed of mechtrode are the most influential parameters 
which affect the bond strength and deposition quality [6-8] in the friction surfacing processes shown in Fig. 1. The thickness- and- width of the coating range from 0.5 to $3 \mathrm{~mm}$ [9]. The same thickness range was obtained by 0.9 of the mechtrode diameter [10]. It is also concluded that the coating width mainly depends on the rotational speed of the mechtrode, while the thickness depends on the traverse speed of the substrate. Friction surfacing applications also include an anti-corrosive coating on industrial blades and worn out parts such as turbine blade tips and wear resistant components [11]. Good deposition was obtained on the coating of AISI316 over high speed steel substrate by the single and the three track method [12]. Even though many researchers have made efforts to study the effects of the friction surfacing from the mechanical and metallurgical aspects, still a need is being felt by the researchers to study the coating of AISI 316 deposited on the medium carbon steels which are utilized in industrial applications. In this study, the Taguchi L9 orthogonal array has been selected to investigate the effects of friction surfacing on mechanical properties. A better understanding of micro-structural and corrosion properties is provided by a statistical approach to the coated material and a corrosion analysis. These two procedures are scanty in earlier studies.

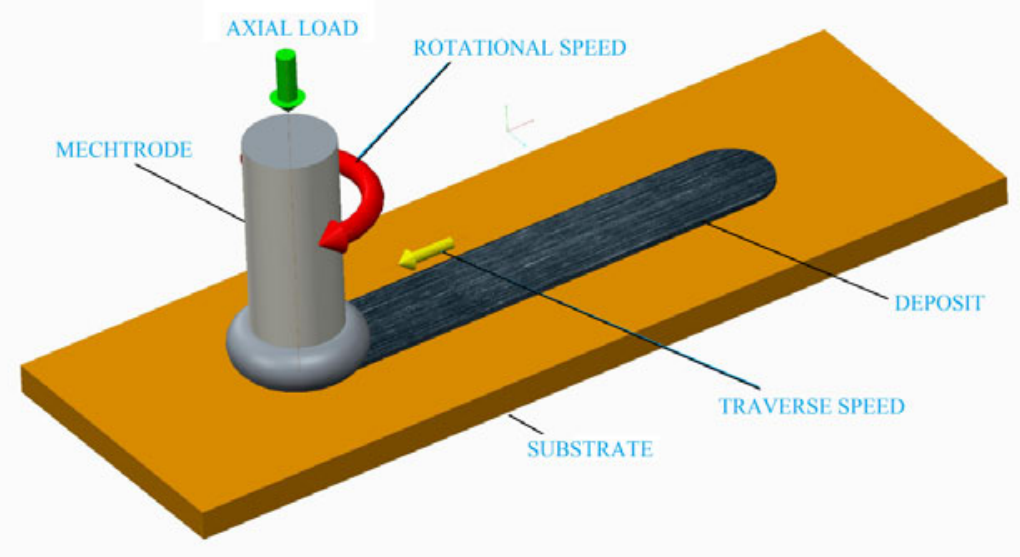

Fig. 1 Friction surfacing process.

\section{Materials and Methods}

An AISI 316 stainless steel rod of $20 \mathrm{~mm}$ in diameter and $120 \mathrm{~mm}$ in length was used as a mechtrode which was machined to obtain an intimate contact with the EN8 (R) base metal used as a substrate in the form $15 \mathrm{~mm} \times 150 \mathrm{~mm} \times 200 \mathrm{~mm}$ plate. Generally, the EN8 base metal is available in untreated condition with tensile strength of $550 \mathrm{MPa}$. In the present study the untreated base metal EN8 is heat treated at $830{ }^{\circ} \mathrm{C}$ and cooled in air; this improves the tensile strength to $850 \mathrm{MPa}(\mathrm{EN} 8 \mathrm{R})$. The tool bottom face and the plate top surface were given a finish grinding so as to provide a flatter rubbing surface. Although this process did not require cleaning, degreasing was carried out to avoid the effects of oxidation; the substrate was cleaned with acetone $\left(\mathrm{CH}_{3} \mathrm{CO}-\mathrm{CH}_{3}\right)$ prior to experimentation. The chemical composition and mechanical properties of mechtrode and base metal are shown in Table 1 and 2. The reagents were purchased from Sigma-Aldrich chemicals and were used without further purification. Table 3 shows the different levels and parameters which were selected based on the trial experiments. The experiments were carried out using a friction surfacing machine with a maximum capacity of $10 \mathrm{kN}$, produced in IIT-Madras, India and supplied by the RV machine Tool Coimbatore. The ram tensile test was conducted on the coated samples in accordance with the MIL-J-24445 (SH) standard. The substrate was machined to form an inner circle or a hole which an annular space between the substrate and the intact coating. Using the standard metallographic procedure, the micro structural analysis was carried out using an inverted metallurgical microscope coupled with the Metal Plus software. Scanning electron microscopy 
was conducted by means of a Carl Zeiss MA15/EVO18 scanning electron microscope. The XRay Diffraction (XRD) method was applied using the $\mathrm{CuK} \alpha$ radiation provided by a Bruker machine with accelerating voltage of $40 \mathrm{kV}$. A corrosion study was conducted by the salt spray method according to ASTM B $117 ; 3.5 \% \mathrm{NaCl}$ solution with a $\mathrm{pH}$ value of 7.1 was used at an air pressure of $0.103421 \mathrm{MPa}$. The temperature in the salt spray chamber was kept under control in the range $33.8-35.1{ }^{\circ} \mathrm{C}$ range. The maximum duration of the experiment was 250 hours; the experiment was continuous without any interruption. Electrochemical Impedance Spectroscopy (EIS) measurements were conducted by an ACM electrochemical impedance analyser (Gill AC Serial No. 1634- Sequencer Version 4). Impedance test was done with the help of a typical three-electrode system; the sample having the highest value of bond strength at the maximum axial load, the minimum traverse speed and the average rotational speed is the sample (T8), as shown in Table 4. The supplementary electrode was a platinum foil; the reference electrode was a standard calomel electrode (SCE), and the samples had an uncovered space of $1 \mathrm{~cm}^{2}$ as a working electrode. The remaining area was masked by insulating cellophane tape. In the EIS analysis, $10 \mathrm{mV}$ amplitude AC signals and a frequency range of $10 \mathrm{kHz}$ to $0.1 \mathrm{~Hz}$ at the open circuit potential (OCP) were applied to the working electrode [12]. The Tafel polarization potential was tested at OCP at a scan level of $0.5 \mathrm{mV} / \mathrm{Sec}$ from $-250 \mathrm{mV}$ to $+250 \mathrm{mV}$. The anodic and cathodic polarization curves obtained were used for identifying the Tafel regions and were extrapolated for getting the corrosion potential $\left(\mathrm{E}_{\text {corr }}\right)$ and the corrosion rate $\left(\mathrm{I}_{\text {corr }}\right)$ in $\mathrm{mm}$ per year. All geometrical dimensions were taken at room temperature $\left(25 \pm 2{ }^{\circ} \mathrm{C}\right)$ and the resultant data was examined using the ZSimp Win software [13 -15].

Table 1 Chemical composition of AISI 316 and EN8 in mass \%.

\begin{tabular}{|l|c|c|c|c|c|c|c|c|c|c|}
\hline Base metal/Elements & $\mathbf{C}$ & $\mathbf{S i}$ & $\mathbf{M n}$ & $\mathbf{P}$ & $\mathbf{S}$ & $\mathbf{C r}$ & $\mathbf{N i}$ & $\mathbf{M o}$ & $\mathbf{N}$ & $\mathbf{F e}$ \\
\hline $\begin{array}{l}\text { AISI316 } \\
\text { (Rod/Mechtrode) }\end{array}$ & 0.079 & 0.99 & 1.99 & 0.04 & 0.02 & 17.9 & 13.8 & 2.7 & 0.10 & Rest \\
\hline $\begin{array}{l}\text { EN8 (R) } \\
\text { (Plate/Substrate) }\end{array}$ & 0.39 & 0.38 & 1.00 & 0.05 & 0.005 & - & - & - & - & Rest \\
\hline
\end{tabular}

Table 2 Mechanical properties of AISI 316 and EN8.

\begin{tabular}{|c|c|c|c|c|}
\hline Base metal & $\begin{array}{c}\text { Yield strength } \\
\mathbf{N} / \mathbf{m m}^{2}\end{array}$ & $\begin{array}{c}\text { Ultimate strength } \\
\mathbf{N} / \mathbf{m m}^{2}\end{array}$ & Elongation\% & $\begin{array}{c}\text { Hardness } \\
\text { (BHN) }\end{array}$ \\
\hline AISI 316 & 525 & 580 & 52 & 170 \\
\hline EN8 (R) & 465 & 850 & 15 & 225 \\
\hline
\end{tabular}

Table 3 Factors and levels of the experiment.

\begin{tabular}{|c|c|c|c|}
\hline Levels/Parameters & $\begin{array}{c}\text { Axial compressive } \\
\text { force, } \\
\boldsymbol{P} / \mathbf{k N}\end{array}$ & $\begin{array}{c}\text { Rotational speed of the } \\
\text { consumable rod/ mechtrode, } \\
\mathbf{N} / \mathbf{r p m}\end{array}$ & $\begin{array}{c}\text { Traverse speed of the } \\
\text { substrate } \\
\boldsymbol{T S} /(\mathbf{m m} / \mathbf{m i n})\end{array}$ \\
\hline Level 1 & 7.7 & 900 & 180 \\
\hline Level 2 & 8.5 & 1220 & 240 \\
\hline Level 3 & 9.2 & 1550 & 290 \\
\hline
\end{tabular}

\section{Results and Discussion}

Table 4 shows the Taguchi L9 orthogonal design matrix with axial compressive force, rotational speed of mechtrode and traverse speed as input parameters and bond strength as the output parameter. The bond strength was obtained by means of the ram tensile strength which is best suited to friction surfaced components developed [16]. In friction stir welding, it was concluded that the amount of material removed from a welded sample is lower than that removed from the base metal, hence wear resistance increases during the processes [17]. Ram tensile strength of $504 \mathrm{MPa}$ was obtained at the minimum traverse speed, while the thickness 
of thin coating was improved by a high axial force [18]; at the medium rotational speed, the coating thickness is minimal so that peeling of the material is minimized. The microstructure of etched EN8 base metal reveals ferrite and pearlite structures with coarse grains distributed in a non-uniform manner; similar results were observed in [19]. The morphology of the mechtrode reveals a small ferrite region in the dark phase while the austenite grain structure in the white phase is predominant as shown in Fig. 2 and 3.

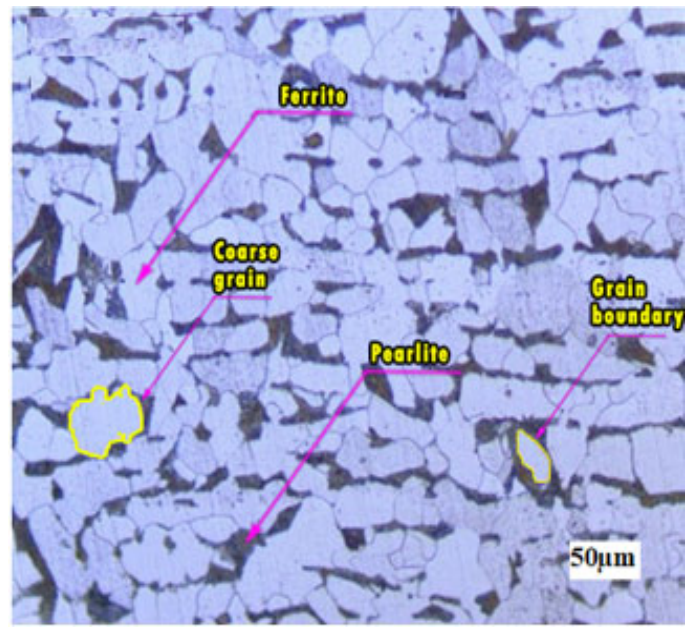

Fig. 2 Microstructure of EN8.

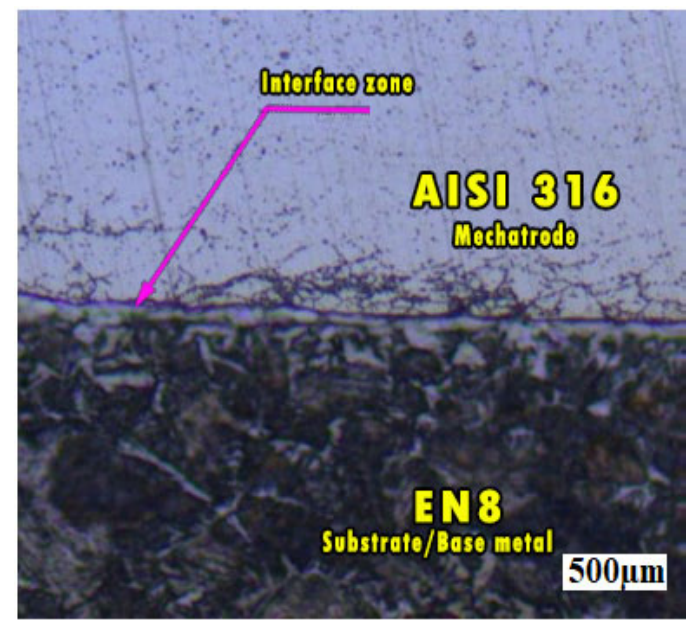

Fig. 4 Cross sectional view of a coated sample.

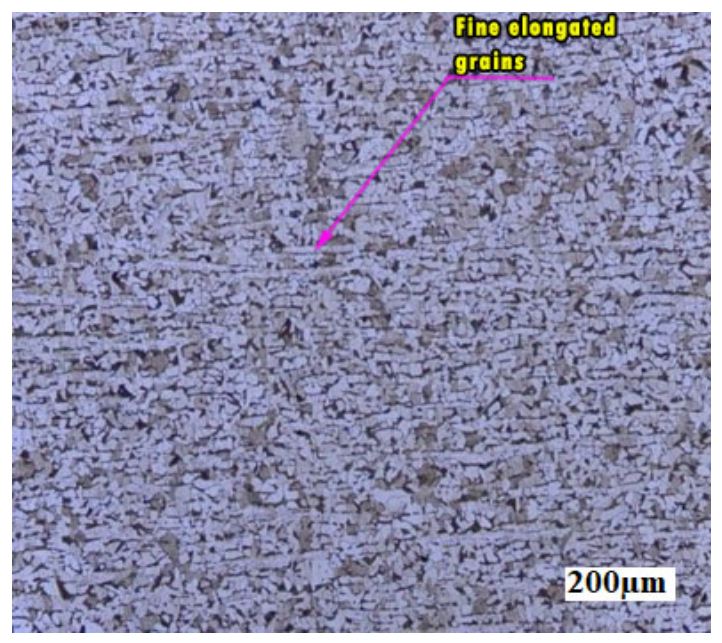

Fig. 3 Microstructure of AISI 316.

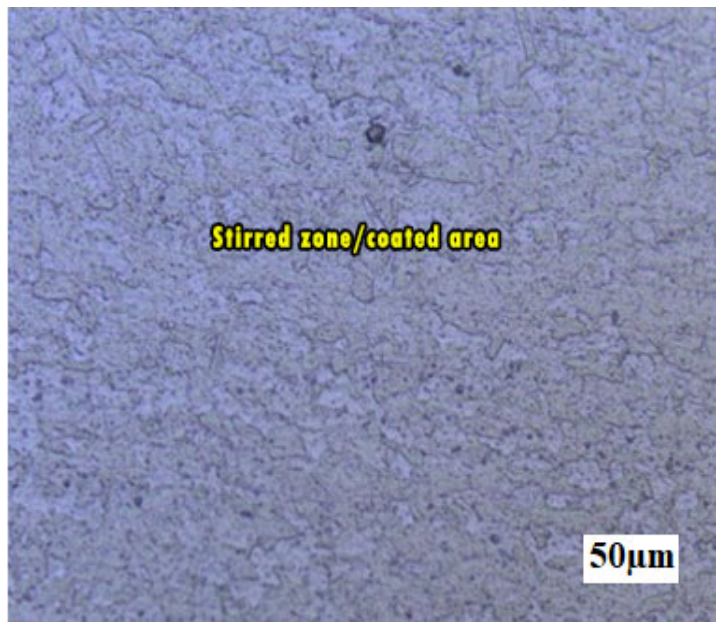

Fig. 5 Stirred zone of AISI 316.

Figure 4 shows the interface zone of the mechtrode and the substrate. One can clearly see that the samples are free from metallurgical defects such as cracks, micro-fissures and also from inter-metallic particles, which improves the integrity of the coating. Figure 5 shows that dynamic recrystallization occurs and dilution is eliminated due to a careful selection of process parameters. These process parameters enable new grains (ASTM -E112) with the average grain size number as 6 to be formed but in a comparatively smaller number than in the received condition due to the fast cooling rate of the plasticization. The $\mathrm{X}$ - ray diffraction analysis was conducted on a polycrystalline material for the 2theta region from 10 to 90 degrees. Using Bragg's law diffraction, three intense peaks at 42.19, 43.12, and 49.07 are observed in Figure 6.The FCC and BCC phases $(\alpha-\mathrm{Fe}$ and $\gamma$-Fe), with miller indices of $1,1,1$ and 2,0,0 respectively, are also shown in this figure. Similar intensity can be found in [20,21]. Table 5 shows several peaks of $\alpha$-Fe content which were observed at the 2 theta values from $40^{\circ}$ to $75^{\circ}$ with the average crystal size of $5.76 \mathrm{~nm}$. 


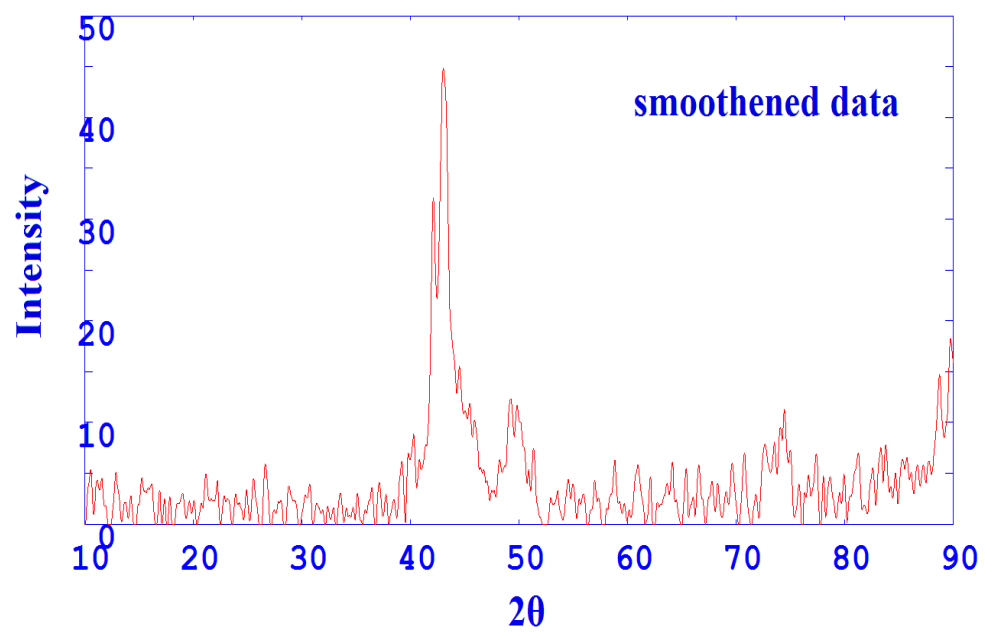

Fig. 6 X-ray diffraction pattern.

Table 4 Taguchi Design matrix for various trials of friction surfacing and its bond strength

\begin{tabular}{|c|c|c|c|c|}
\hline $\begin{array}{c}\text { Sample } \\
\text { No }\end{array}$ & $\begin{array}{c}\text { Axial } \\
\text { compressive } \\
\text { force, } \\
P / \mathbf{k N} \\
\end{array}$ & $\begin{array}{c}\text { Rotational speed of the } \\
\text { consumable rod/ } \\
\text { mechtrode, } \\
N / \mathbf{r p m}\end{array}$ & $\begin{array}{c}\text { Traverse speed of the } \\
\text { substrate } \\
T S /(\mathrm{mm} / \mathrm{min})\end{array}$ & $\begin{array}{c}\text { Bond strength } \\
\mathrm{S} / \mathrm{MPa}\end{array}$ \\
\hline$T 1$ & 7.7 & 900 & 180 & 249 \\
\hline$T 2$ & 7.7 & 1220 & 240 & 301 \\
\hline T3 & 7.7 & 1550 & 290 & 237 \\
\hline$T 4$ & 8.5 & 900 & 240 & 364 \\
\hline$T 5$ & 8.5 & 1220 & 290 & 321 \\
\hline T6 & 8.5 & 1550 & 180 & 451 \\
\hline$T 7$ & 9.2 & 900 & 290 & 413 \\
\hline$T 8$ & 9.2 & 1220 & 180 & 504 \\
\hline$T 9$ & 9.2 & 1550 & 240 & 487 \\
\hline
\end{tabular}

Table 5 Crystallite size table for 2Theta.

\begin{tabular}{|c|c|c|c|}
\hline $\boldsymbol{2 \theta} / \mathbf{d e g}$ & $\boldsymbol{\Theta} / \mathbf{d e g}$ & $\boldsymbol{F W H M} /$ (no unit) & Crystallite size / nm \\
\hline 42.19 & 21.09 & 0.89 & 9.21 \\
\hline 43.12 & 21.56 & 2.08 & 4.02 \\
\hline 49.07 & 24.53 & 2.17 & 4.07 \\
\hline \multicolumn{3}{|c|}{ Average crystallite size } \\
\hline
\end{tabular}

\subsection{Coating geometry (coating width and coating thickness)}

From the bar charts shown in Fig.7 it is evident that the maximum coating thickness has been achieved in the sample T7 due to the application of the maximum axial force of $9.2 \mathrm{kN}$ at the lowest rotational speed. The maximum traverse speed played a vital role in the coating process. The bond strength is also appreciable at this combination of input parameters. The bond strength is maximal for the sample T8 at the maximum axial force and the medium rotational speed; the coating thickness is reduced at the low traverse speed. The traverse speed influences the combination of coating thickness and bond strength. The surface energy developed as an outcome of the frictional resistance determines the thickness of the coating. The lower traverse speed reduced the coating thickness as well as the bond strength. The coating width remains similar irrespective of the influence of other input parameters. Similar results can be found in [22,23]. 


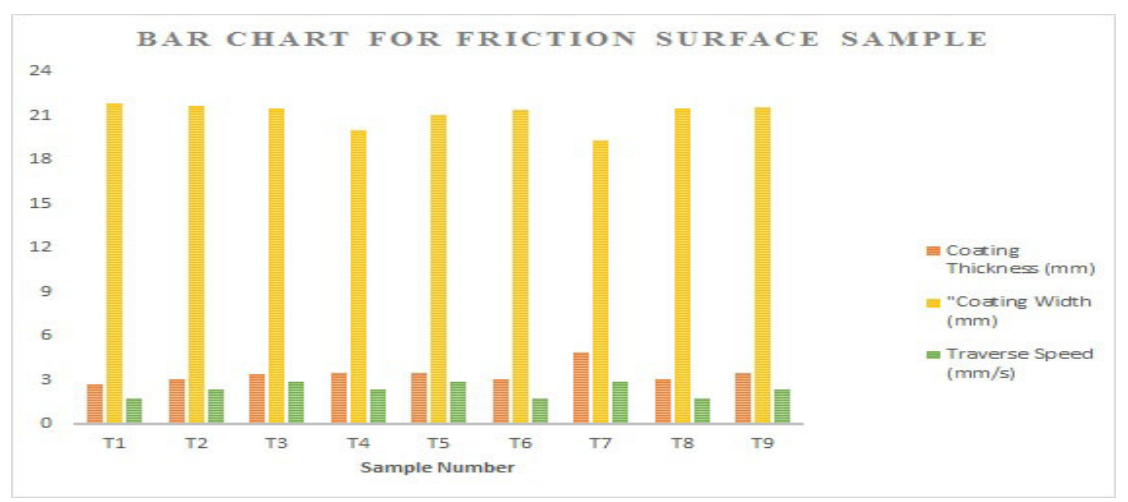

Fig. 7 Correlation between the samples and the coating geometry.

\subsection{Corrosion analysis}

\subsubsection{Salt spray method}

Results of the interpretations made for the AISI316, AISI316-EN8 system and EN8 base metal after 50 and 250 hours of salt-spray test are shown in Table 6 . The table provides details of the salt spray test results of bonded pieces before and after exposure to mist environment. No corrosion products were observed on the coated surface during the salt spray test. As the EIS showed, the resistance exhibited by EN8 was rather poor in comparison with those of the other two coatings (Mechtrode AIS316 and AIS316-EN8) considered in the study. There was neither corrosion nor coating imperfections on the main body of the sections shown in [24]. However, rusting was not observed on AISI316-EN8. Hence, the AISI316EN8 formulations produced quite good outcomes without any major loss of bonding, even after 250hours of the salt-spray exposure. On the other hand, the EN8 substrate shows the resistance to salt-spray pitting.

Table 6 Corrosion behavior for two different periods of time

\begin{tabular}{|c|c|c|}
\hline Coating system & Observation after 50 hours & Observation after 250 hours \\
\hline AISI316 & No corrosion & No corrosion \\
\hline AISI316-EN8 & Pale yellow rust & Light brown rust \\
\hline EN8 & Dark yellow rust & Dark brown rust \\
\hline
\end{tabular}

\subsubsection{Electrochemical studies}

Metals have a small tendency in the marine atmosphere and the rate of corrosion is higher in the same medium. In this connection, the base metal EN8 and its corrosion tendency in the marine has been chosen for this study. A basic potentiodynamic polarization study showed a higher corrosion tendency of the base metal in the salty medium. In this study, the focus was on the attempt to change the active corrosion tendency of the base metal to passivity. This study also identifies the relationships between the input metals and the process response in order to obtain a new design. Passivity is a condition found in some metals and alloys that are capable of resisting corrosion due to the formation of a surface film. These films form under highly oxidizing conditions or due to anodic polarizations. This definition excludes metals possessing a simple barrier film with reduced corrosion at active potential and small anodic polarization. Also, it should be pointed out that insoluble compounds formed by dissolution and re-precipitation are less persistent and less protective than the oxide films formed in situ on the metal surface. This is an exceedingly important characteristic found in several structural metals such as iron, chromium, nickel titanium and aluminium and their alloys, among which the most notable example is EN-8. 
Electrochemical behaviour was studied in three regions: (i) substrate (ii) coating base material (iii) coated surface in chloride ions medium with $3.5 \%(\mathrm{NaCl})$, the electrochemical behaviour was investigated by potentiodynamic polarization curves or the Tafel curve, Nyquist and Bode plots. To assess the corrosion state the $\mathrm{E}_{\text {corr }} \& \mathrm{I}_{\text {corr }}$ parameters are interpreted. Using this technique, the current density between potential of the electrode, and reference electrode is recorded by a continuous scan. The potential of a coated electrode is altered at a selected rate by passing of a current through the salt electrolyte. The corrosion rate is assessed through the Tafel extrapolation method. The corrosion potential of the EN8 steel in the aerated $0.5 \mathrm{M} \mathrm{NaCl}$ solution $\mathrm{pH} \sim 6,1$ exists between -8.00 and $-7.7 \mathrm{~V}$. It is clearly shown that the alloy material is highly reactive in the salty medium and that is corrodes fast. To reduce the rate of corrosion and increase the stable passive surface in a salty medium, the material was coated by the AISI316 alloy and the coating effect was studied after 15 minutes. The outcome of this electrochemical study showed improvement on the surface of the EN8 alloy and the potential increased between -7.5 and $-7.2 \mathrm{~V}$. This research also investigated successfully the effects of chromium, nickel and molybdenum alloys in the AISI316 stainless steel on the EN8 alloy. The low cost EN8 with a high corrosion tendency is protected by a small amount of of AISI316 alloy in the form of a coating with $3.06 \mathrm{~mm}$ in thickness. This improved passivity due to the fact that AISI316 fine particles penetrated the surface film of EN8. The coated EN8 metal can be used for ship hulls because the material is protected from corrosion and the adhesion of marine organism.

The EIS procedure is extensively used for the characterization of coatings. The sinusoidal signals (potential) obtained by the applied low amplitude, do not interrupt the equilibrium conditions of the system. Different electrical parameters of the system, such as resistance, capacitance and dielectric constant $[25,26]$ were obtained from this experiment. The obtained values are used to plot the polarization, and to create the Nyquist and Bode plots. Figures-.8-11 show typical Nyquist plots obtained for the AISI316 coating and the respective base alloy EN8 base alloy. The plots show the corrosion control on the EN8 metal surface and the stable passivity of AISI316 alloy in the electrolyte.

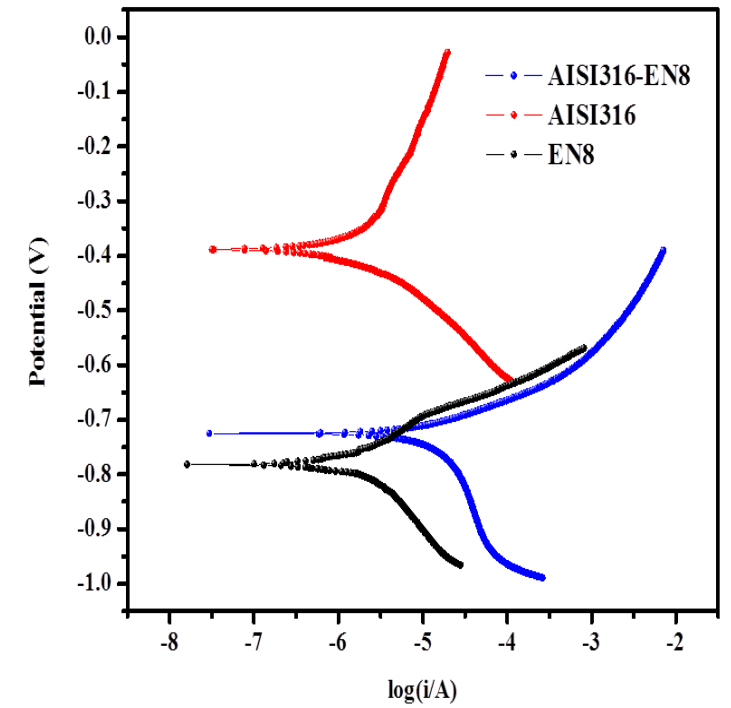

Fig. 8 Polarization response of AISI316, AISI316-EN8 and EN 8 in $3.5 \% \mathrm{NaCl}$

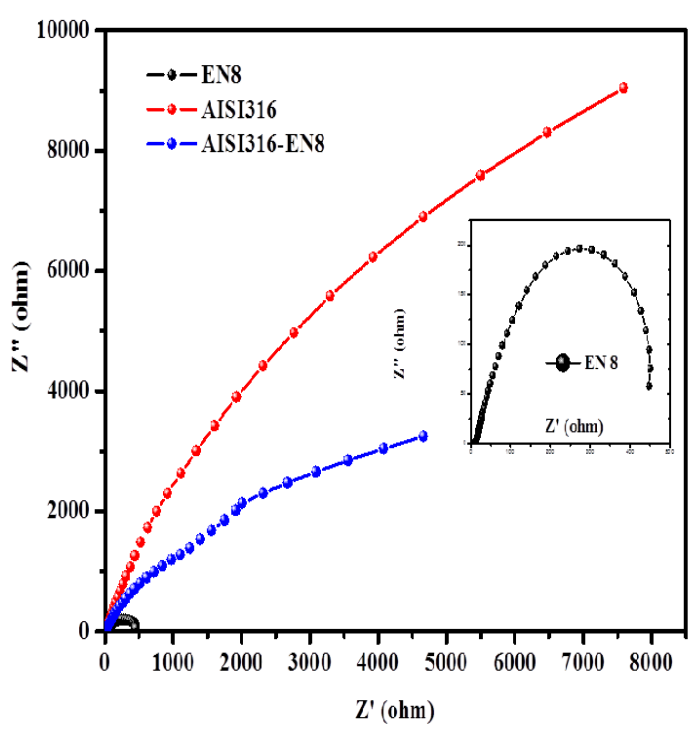

Fig. 9 Nyquist plot of AISI316, AISI316-EN8 and $\mathrm{EN} 8$ in $3.5 \% \mathrm{NaCl}$

Stable passivation was obtained on the friction surfaced components which have a possibility to form a thin film on the coated surface due to the presence of chromium and nickel elements [27, 28]. 
R. G. Sahaya Nixon, R. Sathish, B.S. Mohanty

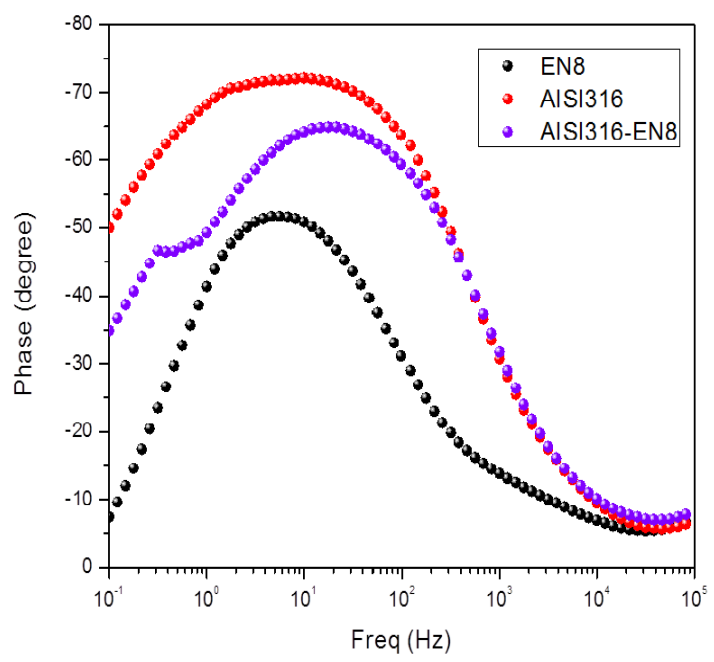

Fig. 10 Bode plot of AISI316, AISI316-EN8, and EN 8 in $3.5 \% \mathrm{NaCl}$
Characterization of a Friction Surfaced Stainless Steel Coating on Medium Carbon Steel

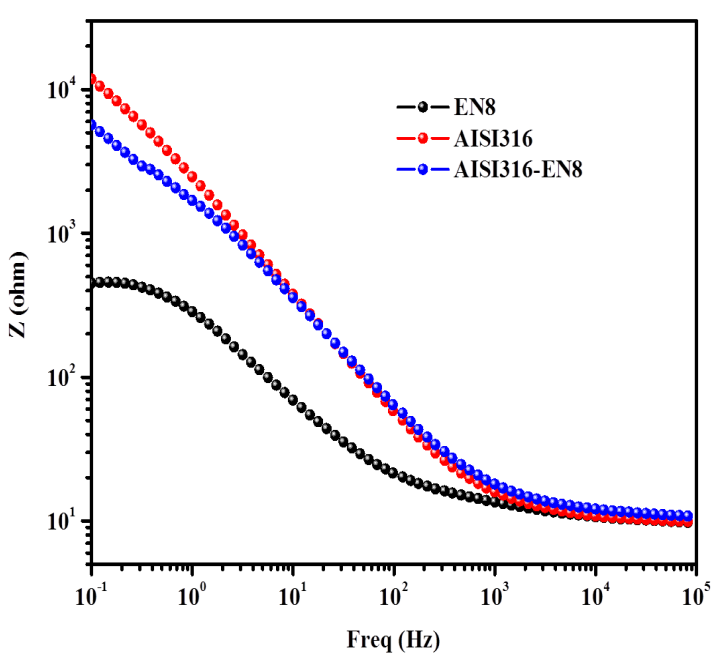

Fig. 11 Phase angle plot of AISI316, AISI316-EN8, and EN 8 in $3.5 \% \mathrm{NaCl}$.

Similar studies were carried out revealing that when stainless steel was in a physical contact with aquatic surroundings, a light coat of chromium oxide offers a better corrosion resistance [29]. From the curve, one can see that the AISI 316 mechtrode shows high corrosion resistance; when compared to the substrate, the coated surface exhibited satisfactory resistance. The EIS study was conducted to validate the results. The Nyquist plot gave the appearance of being vis-a- vis the real part of impedance ( $\left.Z^{\prime}\right)$ and imaginary part impedance (Z') of AISI316-EN8, but the shapes produced by the curve with respect to the diameter were not alike(i.e.)the large loop diameter indicated a high corrosion resistance rate. It reveals that the bonded material (AISI316-EN8) and the mechtrode (AISI316) have extremely good corrosion resistance, whereas the EN8 substrate showed poor resistance to corrosion, as predicted. The measurements from the EIS indicate fair corrosion resistance with polarization [31]. The molybdenum content in the coated material improves the passivity of the MoO42 film, due to differential aeration on the surface; this will not allow the surface degradation of the oxide layer. Also, nickel improves the chromium oxide in the coating and thus enables the creation of a re-passivation property [32]. Stable passivation occurred due to the presence of chromium element which acts as a ferrite former. Performance of the coatings pertaining to the protection from corrosion has been evaluated with the help of the useful parameter of the phase angle at high frequencies. The dielectric pathways are preferred by the flowing current, when the coating substance provides very high resistance. A point of interest to be noted is that the phase angle values of AISI316 immersion in the electrolyte were at $70^{\circ}$, indicating a capacitive behaviour. However, the phase angle values shown in Fig.11 for the AISI316-EN8 system exposure to electrolyte become more resistive $\left(65^{\circ}\right)$ than those for EN8 $\left(45^{\circ}\right)$. It is concluded that the stability of the coating in a corrosive system is demonstrated by its capacity to resist corrosion during the period of immersion $[33,34]$.

\section{Conclusions}

A novel attempt has been made to replace the substrate material by the EN series of medium carbon steel materials, which exhibit better corrosion resistance, improved mechanical properties, and also good machinability. These materials have a wide range of commercial applications in corrosive environments, e.g. ship hull, stern and marine support structures.

The friction surfacing processes was successfully conducted on the EN8 medium carbon steel plate using AISI316 as the coating material. Maximum ram tensile strength of $504 \mathrm{MPa}$ was obtained by an axial load of $9 \mathrm{kN}$ at the medium rotational speed (1220rpm) and low traverse speed.

The samples coated with AISI 316 are free from metallurgical defects such as cracks, micro-fissures and porosity, and also from inter-metallic particles which reduce the integrity 
of the coating. The coated metal has two peaks with $\alpha$-Fe content, which were observed at 2 theta values from $40^{\circ}$ to $75^{\circ}$ with an average crystal size of 5.76 nano meters. On the AISI316 mechtrode, no corrosion was found after 50 and 250 hour tests.

On the base metal EN8, dark yellow rust and dark brown rust are observed after 50 and 250 hours, respectively. After 250 hours, light brown rust is observed when the two materials are combined.

Stable passivation was obtained on the friction surfaced components which have a possibility to form a thin film on the coated surface due to the presence of chromium and nickel elements.

It is found that the stability of the coating in a corrosive environment is demonstrated by its capacity to resist corrosion during the period of immersion in the electrolyte at $70^{\circ}$, indicating a capacitive behaviour. However, the phase angle for the AISI316-EN8 system became more resistive $\left(65^{\circ}\right)$ than for EN8 $\left(45^{\circ}\right)$ of exposure to the electrolyte.

\section{Acknowledgements}

The authors would like to thanks Mr. R. Rangan senior Technician, IITM, Chennai \& St. Joseph's college of Engineering for their continuous encouragement and permission to accomplish the experimental work.

Conflicts of Interest: The authors declare no conflict of interest.

\section{REFERENCES}

[1] Palani, P. K.; Murugan, N. Sensitivity analysis for process parameters in cladding of stainless steel by flux cored arc welding, Journal of Manufacturing Process, 8 (2) 90-100. (2006).

https://doi.org/10.1016/S1526-6125(06)80004-6

[2] Mansford, R. E. Surface coatings-4 Sprayed coatings, Tribology, 1972, 220-224.

[3] Nicholas, E.D.; Thomas, W.M. Metal deposition by friction welding. Welding Journal, 1986, 17-27.

[4] Thomas, W.M.; Nicholas E.D.; Kallee S.W. "Friction based Technologies for Joining and Processing", TWI Ltd., 2001.

[5] Vitanov, V.I.; Voutchkov, I.I. Process parameters selection for friction surfacing applications using intelligent decision support, Journal of Material Processing and Technology. 2005, 159, 27-32. https://doi.org/10.1016/j.jmatprotec.2003.11.006

[6] Vitanov, V.I.. Voutchkov, I.I.; Bedford, G.M. Decision support system to optimize the friction surfacing process. Journal of Material Processing and Technology, 2000, 107, 236-242. https://doi.org/10.1016/S0924-0136(00)00710-X

[7] Chandrasekaran, M.; Batchelor, A.W.; Jana, S. Study of the interfacial phenomena during friction surfacing of aluminum with steels, Journal of Material Science, 1997, 32, 6055-6062. https://doi.org/10.1023/A:1018635732454

[8] Rafi, H.K.; Ram, G.D.J.; Phanikumar G.; Rao K.P. Friction Surfaced Tool Steel (H13) Coatings on Low Carbon Steel: A Study on the Effects of Process Parameters on Coating Characteristics and Integrity, Surface Coating Technology, 2010, 205-232

[9] Voutchkov, I. Jaworski, B.; Vitanov, V.I.; Bedford, G.M. An integrated approach to friction surfacing process optimisation, Surface and Coatings Technology, , 141, 26-33. https://doi.org/10.1016/S0257-8972(01)01127-6

[10] Khalid Rafi, H.; Janaki Ram, G. D.; Phanikumar G.; Prasad Rao, K. Friction Surfacing of Austenitic Stainless Steel on Low Carbon Steel: Studies on the Effects of Traverse Speed. Proceedings of the World Congress on Engineering, 2010, Vol II WCE June 30 - July 2, 2010, London, U.K.

[11] Macedo, M.L.K.; Pinheiro, G.A.; Santos, J.F.; Strohaecker, T.R.; Deposit by friction surfacing and its applications. Welding International, 2010, 24, 422-431. https://doi.org/10.1080/09507110902844535

[12] Ravi Kumar Somnath Chattopadhyaya Aniruddha Ghosh Pedro Vilaca Ratnesh Kumar Madhulika Srivastava Mohammad Shariq Rupam Triphathi "Characterization of Friction Surfaced Coatings Of AISI 316 Tool Over High-Speed-Steel Substrate (2017) pp 61-76, DOI: 10.21278/TOF.41206.

[13] Dong, CF, Sheng, H, A, YH, Li, XG, Xiao, K, Cheng. YF, "Corrosion of 7A04 Aluminum Alloy under Defected Epoxy Coating Studied by Localized Electrochemical Impedance Spectroscopy." Progress in Organic Coating, (2010) 67 269-273. https://doi.org/10.1016/j.porgcoat.2009.11.004

[14] Sinebryukhov S. L., Gnedenkov A. S., Mashtalyar D. V., Gnedenkov S. V. PEO-coating/substrate interface investigation by localised electrochemical impedance spectroscopy. Surface and Coatings Technology, 2010, Vol. 205, 1697-1701. https://doi.org/10.1016/j.surfcoat.2010.05.048 
[15] N. Pebere, T. Picaud, M. Duprat, and F. Dabosi, Evaluation of corrosion performance of coated steel by the impedance technique, Corrosion Science,1989 vol. 29, no. 9, 1073-1086. https://doi.org/10.1016/0010-938X(89)90045-0

[16] Mansfeld F. Use of electrochemical impedance spectroscopy for the study of corrosion protection by polymer coating, Journal of Applied Electrochemical science, 1995.

[17] Ratnesh Kumar, Somnath Chattopadhyaya,Sergej Hloch, Grzegorz Krolczyk, Stanislaw Legutko. Wear characteristics and defects analysis of friction stir welded joint of aluminium alloy 6061-T6 Eksploatacja $i$ Niezawodnosc - Maintenance and Reliability, 18 (1), pp. 128 - 135 (2016).

[18] Enright, T.J.; Sharp, W.F.; Bergmann O.R. Explosive bonding dissimilar metals, Metal Progress, 1970.

[19] Gandraa, J.; Perei, D.; Miranda, R. M.; Vilaça, P. Influence of process parameters in the friction surfacing of AA 6082-T6 over AA 2024-T3, Forty Sixth CIRP Conference on Manufacturing Systems, 2013, 341346. https://doi.org/10.1016/j.procir.2013.05.058

[20] Sathish, R, Vaddi Seshagiri Rao. Mechanical and Metallurgical Characterization of Dissimilar Weld Joints Using Continuous Direct Drive Friction Welding, Engineering Transactions, 2016, 64(2) 241-252.

[21] P. Saravanan, D. Duraibabu, S. A. Kumar, Development of Environmentally Acceptable Nano-Hybrid Coatings for Bio-Fouling Protection, Advanced Materials Research, 2014 Vol. 938, 269-274. https://doi.org/10.4028/www.scientific.net/AMR.938.269

[22] Masanori Tsunekawa, Mamiko Ishikawa, Masaru Nakajima and midori hashiguchIShiga University Faculty of Education Minutes Humanities, Social Sciences and Natural Sciences 2013, 63, 31-34.

[23] Francisco J. Baldenebro-Lopez, Cynthia D. Gomez-Esparza Ramon Corral-Higuera, Susana P. Arredondo-Rea, Manuel J. Pellegrini-Cervantes Jose E. Ledezma-Sillas, Roberto Martinez-Sanchez and Jose M. Herrera-Ramirez Influence of Size on the Microstructure and Mechanical Properties of an AISI 304L Stainless Steel-A Comparison between Bulk and Fibers Materials 2015, 8, 451-461; doi:10.3390/ma8020451 pp451-461.

[24] Tarunkumar Jujare Arunkumar, Satish v Kailas, Udaya Bhat Friction surfacing of mild by copper : A feasibility study, Procedia of Material science, 2014, 1300-1307.

[25] Orazem, M.E.; Tribollet, B. Electrochemical Impedance Spectroscopy; Wiley: New York, NY, USA, 2008. https://doi.org/10.1002/9780470381588

[26] Fayyad, E.M.; Almaadeed, M.A.; Jones, A.; Abdullah, A.M. Evaluation techniques for the corrosion resistance of self-healing coatings. International Journal of Electrochemical Science, 2014, 9, 4989-5011.

[27] Dhoke, S. K.; Khanna, A. S.; MangalSinha, T. J. Prog. Org. Coat. 2009, 64, 371-382. https://doi.org/10.1016/j.porgcoat.2008.07.023

[28] Malik, A.U.; Siddiqi, N.; Ahmad, S; Andijani, I.N. "The Effect of Dominant Alloy Additions on the Corrosion Behaviour of Some Conventional and High Alloy Stainless Steels in Seawater". Corrosion Science, 1995, 37, 1521-1535. https://doi.org/10.1016/0010-938X(95)00043-J

[29] Lippold, J.C.; Kotecki, D.J. Welding Metallurgy of Stainless Steel. Wiley-Inter science, New Jersey, 2005.

[30] Ramesh Puli and G.D. Janaki Ram. (2012) Corrosion performance of AISI 316L friction surfaced coatings. Corrosion Science 62, 95-103. https://doi.org/10.1016/j.corsci.2012.04.050

[31] Saravanan, P.; Aparna, S.; Kumar, S. A.; Duraibabu, D. Current Bionanotechnology, 2015, 1(1), 37-50. https://doi.org/10.2174/2213529401666150304234007

[32] Kim, J. ; Kwon, H. Effects of Tungsten on Corrosion and Kinetics of Sigma Phase Formation of $25 \%$ Chromium Duplex Stainless Steels, Nace International, 1999.

[33] Hsu, C. I.; Wang, G. L.; Ger, M. D.; Hou, K. H. Corrosion Behavior of Electroless Deposited NiP/BN(h),Composite Coating,2016,4352-4361. https://doi.org/10.20964/2016.06.19

[34] Aperador, W.; Duque, J.; Delgado, E. Electrochemical Impedance Studies on Tribo corrosion of Coatings AlxTi1-xN Deposited on Austenitic Steels, International Journal of Electrochemical Science, 2016, 11, $1070-1079$.

Submitted: $\quad 22.9 .2017$

Accepted: $\quad$ 08.5.2018
Assoc. Professor R.George Sahaya Nixon gsnixons@gmail.com

St. Joseph's College of Engineering,

Chennai, Tamil Nadu, India.

Assoc. Professor R. Sathish sai_27r123@rediffmail.com

St. Joseph's College of Engineering

Chennai, Tamil Nadu, India.

Professor B.S.Mohanty

Easwari Engineering College

Chennai, Tamil Nadu, India. 